\title{
Breve Discussão sobre a Tríade: Estado, Educação e Economia
}

\section{Resumo}

presente artigo pretende levantar breves questões sobre a crise do setor educacional e o novo papel do Estado na economia, procurando esboçar a predominância do discurso neo-liberal da revalorização da escolaridade vinculada à formação de mão de obra para o mercado, em detrimento da educação como meio de construção da cidadania.

\section{Abstract \\ The present article intends to arise brief questions about the educational sector crisis and the State new role in the economy, looking for designing the pre- dominance of the neoliberal speech of the school apprenticeship reevaluation attached to manpower formation for the market, with prejudice of the edu- cation as a way of citizenship construction.}

Dentro do vasto universo de estudo da ciência econômica no Brasil, a grande maioria dos livros, pesquisas e mesmo das teses acadêmicas vem dando ênfase ao crescimento econômico, aos problemas estruturais e conjunturais da organização econômica, industrialização, estabilização econômica, globalização etc.

Pouco tem sido, no decorrer das duas últimas décadas, o espaço concedido ao aprofundamento do estudo do desenvolvimento econômico sob a ótica da educação. O sistema educacional de uma nação adquire grande relevância enquanto agente contribuidor e sedimentador do desenvolvimento, seja produzindo novos conhecimentos e pesquisas, seja elevando o nível educacional da população, preparando tanto cidadãos atuantes na sociedade como mão-de-obra qualifica- da reclamada pelo sistema produtivo. No entanto, apesar do exaustivo discurso sobre as mudanças na política educacional, nada sinaliza para uma melhoria da qualidade da educação no país.

As atuais transformações políticas, econômicas e sociais que desencadearam a crise atual do Estado são oriundas de seu próprio papel desde a década de 30, papel este que, embora desfigurado, se mantém . O Estado sempre foi o Estado da classe dominante.

A partir de 30, o Estado passa a ser o núcleo organizador da sociedade e alavanca a construção do capitalismo industrial no país. Nas décadas de 40 e 50, consolida-se o Estado desenvolvimentista que associado ao capital estrangeiro expande o mercado interno, cria condições de produção através da instalação de indústrias de base e de bens de capital. No final da década de 50 , assume sua preferência pelas multinacionais. As classes proprietárias (tanto industriais quanto agrárias) se apropriam do produto da modernização econômica excluindo a maioria da população.

Em 64, o regime militar autoritário mantém o pacto desenvolvimentista estimulando a expansão do setor financeiro nacional associado ao internacional, exclui a participação política e torna ilegal qualquer forma de associação popular. Durante o regime, cria-se o II PND que visava transformar o país em uma nação-potência em meio à crise internacional. $\mathrm{O}$ Brasil industrializou-se e a população concentrou-se nas cidades, gerando o proletariado urbano e a classe média.

Nos anos 80, além da crise econômica, entra em crise a relação poder político e sociedade, sendo uma década marcada pela alteração no tipo de Estado que as elites pleiteavam. $\mathrm{O}$ novo

* Mestre em Economia FGV-SP - Professora de Economia das Faculdades Integradas "Campos Salles", PUC-SP e FAAP. 
modelo está associado à recuperação do papel da empresa privada e do mercado em contraposição à proteção de mercado, baixa produtividade e regulamentação. No modelo liberal, o Estado, apontado como ineficiente, deve reduzir-se e voltar-se para as questões sociais. $\bigcirc$ neoliberalismo impõe um modelo para a atuação do Estado: ajustam-se as economias, redefine-se o formato institucional e sua atuação na economia e surge um modelo único: o Estado Mínimo.

As recentes discussões a respeito da crise do Estado nos levam a questionar as "profecias" a respeito dos rumos da sociedade, não só mundial, mas principalmente brasileira. Apesar dos principais elementos da crise serem de caráter econômico, pelo menos durante as duas últimas décadas, enfrentou-se uma crise global, não somente na esfera econômica, mas também na social, política e cultural. Na década de 70, ocorreram mudanças definitivas na morfologia da sociedade com a migração da população rural para os centros urbanos. Os cinturões de pobreza nas cidades se expandiram e, no início dos anos 80 , surge uma massa de marginalizados resultante da crise econômica. Conjuntamente, foi fortalecida a cultura de massa através da globalização da informação a serviço do consumismo. Ao mesmo tempo, o Estado se viu ultrapassado em todas as suas dimensões, principalmente como provedor de serviços públicos. A crise acentuou o déficit público, sucateou equipamentos, baixou a remuneração de pessoal e afetou a qualidade do que já era deficiente, somando-se a ineficácia burocrática.

Dentro deste contexto, com a abertura, a conquista da democracia vem acompanhada de uma grande desordem na definição do novo papel da sociedade. Num mundo onde todos procuram o bem estar geral e o Welfare State está em crise, o mercado torna-se o mecanismo mais eficiente para realizar esses anseios, segundo os neoliberais, ou pelo menos o seu discurso. Mas a grande questão está relacionada à participação da sociedade civil - que ainda está latente - que poderá ser capaz de responder às suas próprias demandas e ajudar a construir a cidadania.

Neste momento, faz-se necessário retomar um planejamento educacional sério, exigindo-se das instituições educacionais e da sociedade sua responsabilidade sobre o ensino. Para tanto, é necessário reafirmar que sempre que se pretenda correlacionar o sistema educacional com o desenvolvimento econômico e social, deve-se analisar o poder e os limites dos agentes participantes deste processo.

Apesar de alguns avanços no sistema educacional brasileiro e dos investimentos governamentais, a deficiência ainda é gritante e, portanto, cabe indagar: por que não foram alcançados integralmente os objetivos propostos nos últimos anos? Que razões impediram que o objetivo da universalização do ensino básico não fosse atingido e eliminado o analfabetismo dos jovens e adultos? As falhas aconteceram no processo de formulação dos planos ou as deficiências residem na fase de sua implementação? Existe a possibilidade de um novo modelo educacional que promova o desenvolvimento econômico, dado um mundo onde as novas tecnologias mudam a uma velocidade alucinante? O Estado deve ser executor das políticas educacionais ou apenas um agente fiscalizador? É ele o único responsável pela educação e pela escolha do que é melhor para a sociedade?

Existem diversos problemas que podem ser detectados, mas os problemas econômicos e sociais da educação são agravados pelas inconsistências administrativas dos governos e pela falta de uma opção política, no sentido de priorizar realmente as questões sociais. Com certeza, as deficiências existentes na administração pública brasileira se refletem na eficiência do sistema de ensino.

"Muitos dos problemas educacionais têm a sua origem na excessiva centralização dos recursos públicos, na rigidez do processo decisório e na ambigüidade gerada pelas competências concorrentes". (I PND-NR, p. 187)

problema econômico da educação e seus desdobramentos na esfera social podem estar 
sendo agravados pela falta de decisão política, pela inconsistência administrativa e pelas imperfeições dos processos de planejamento.

Atualmente, a discussão sobre educação, sistema de ensino e políticas governamentais está sendo retomada por alguns economistas da América Latina, em decorrência principalmente da globalização da economia e da competitividade internacional. Os chamados Tigres Asiáticos, cujo crescimento econômico dos últimos anos assombrou o mundo, são usados como modelo ideal de ensino de massas, por atender à necessidade de formação de mão-de-obra. Este modelo não pode nem deve ser fielmente reproduzido no caso brasileiro, pois a história e a cultura desses países são completamente diferentes.

Observa-se a inexistência de um diagnóstico adequado a respeito da baixa qualidade de ensino no Brasil, apesar das estatísticas comprovarem uma considerável evolução quantitativa.

O crescimento econômico é caracterizado por mudanças de ordem quantitativa, ou seja, pela expansão da riqueza de um país, que pode ser medida pelo Produto Interno Bruto, pela população economicamente ativa, etc. $\mathrm{O}$ crescimento econômico pode ocorrer na mesma proporção do crescimento da pobreza, ou seja, pode ser um crescimento com desigualdade. Para alguns economistas, uma economia deve primeiro passar por esta fase, para depois partir para o desenvolvimento.

Já o desenvolvimento econômico é marcado por transformações qualitativas, estando diretamente ligado ao padrão social que um país pode proporcionar aos seus cidadãos. Normalmente é medido pelo nível de distribuição de renda, acesso à saúde e educação, ou seja, genericamente, pelo nível de bem-estar da sociedade. Para outros economistas, o desenvolvimento deve acompanhar o crescimento como única forma de se atingir o progresso econômico. Este configura a sedimentação das transformações quantitativas e qualitativas ocorridas em uma sociedade, para onde convergem os interesses econômicos, sociais e políticos.
O conceito de educação está ligado à cultura da comunidade a que serve. Educar significa revelar ou extrair de uma pessoa algo potencial e latente. A educação é uma totalidade e não uma parte. Constitui o conjunto de conhecimentos, capacidades, atitudes e valores necessários, para que as pessoas sobrevivam, melhorem e continuem aprendendo. A educação formal (o ensino escolar) e a informal (aprendida no convívio com a comunidade, a família, a igreja etc.) compõem o direito de qualquer indivíduo enquanto cidadão.

No mundo todo, vive-se um momento de revalorização da escolaridade vinculada à difusão das novas técnicas de automação e de organização do trabalho. É dominante a idéia de que a competitividade econômica de uma nação depende da estrutura que ele dispóe para permitir a qualificação da mão-de-obra.

A preocupação com a escolaridade ressurge anos após o advento da Teoria do Capital Humano, a qual provocou grande polêmica entre economistas e educadores. Os economistas viam a educação como forma de qualificar mão-deobra futura, como se a educação pudesse ser tratada como qualquer outro bem material. Os educadores, por outro lado, viam na teoria do capital humano um processo de subordinação não só ao capital, como também aos governos.

É verdade que a educação está diretamente ligada e é condição para a eficiência econômica, existindo numerosos estudos empíricos a respeito que corroboram esta afirmação, pois as demandas por tipos de trabalho, que o sistema produtivo "faz" ao educacional, dependem do estágio em que se encontra a economia.

Na Segunda Revolução Industrial, com a incorporação de métodos científicos aos processos produtivos, exigiu-se que alguns trabalhadores tivessem algumas qualificações mínimas, ao contrário da Primeira Revolução Industrial, onde a desqualificação permitia inclusive a utilização de mão-de-obra infantil. Durante o século XX, o fordismo e o taylorismo se impõem como processo produtivo, criando uma 
produção de massa e permitindo a incorporação do trabalho industrial sem a necessidade de qualificação prévia, pois podia-se treinar no próprio local de trabalho. $O$ fordismo-taylorismo permitiu a simplificação do trabalho e, conseqüentemente, menor demanda dos requisitos fornecidos pelo sistema educacional.

Os países onde a democracia e a noção de cidadania já estavam instaladas deram continuidade ao processo de ampliação do ensino, onde o caráter político se impôs às necessidades econômicas. Com certeza, este não foi o caso do Brasil.

As carências materiais vivenciadas pela maior parte dos brasileiros aparecem nitidamente nos níveis de distribuição de renda, muito pior que em muitos países com crescimento econômico menos acentuado. $\mathrm{O}$ problema é que no Brasil, desde os anos 50, optou-se pelo crescimento ao invés do desenvolvimento. A partir deste processo, consolidou-se o que se pode chamar de "cidadania relativa", ou seja, uma cidadania excludente e discriminatória (os Governos brasileiros têm sempre se pautado mais pela lógica da acumulação do que pela lógica distributiva). Nesta década, principalmente, acentuou-se ainda mais a discriminação social no país, o que em nossa avaliação não passa somente pelas diferenças de cor, sexo ou raça, mas, principalmente, pelo poder econômico do indivíduo.

Nas últimas décadas, os gastos com investimento e manutenção na área da educação foram defendidos fortemente pelo discurso "desenvolvimentista”, com ênfase ao ensino básico e ao ensino técnico. Porém, os gastos se voltaram fortemente para as universidades, atendendo não só a demanda da classe média urbana, que via na ampliação do ensino superior uma forma de ascensão social, mas também da política que visava formar mão-de-obra de melhor qualificação, para atender à concepção de Tecnoestrutura que emergia no país (este conceito está muito bem explicado em Galbraith, 1982, p.269).

Apesar de tudo, para o bem ou para o mal, os governos têm aumentado o número de vagas nas escolas. Esta, entretanto, é uma evolução em termos quantitativos, pois a qualidade de ensino continua deixando muito a desejar.

A incongruência existente é que não se gasta pouco em educação. A Constituição determina que a União aplique, no mínimo, 18\% da receita dos impostos e que os estados e municípios não apliquem menos que $25 \%$ de suas receitas.

Esses índices, porém, pouco dizem sobre a eficiência do ensino (alfabetização, capacidade de redação, conceitos aritméticos etc.), pois sabe-se que parte significativa do orçamento para a educação destina-se a gastos burocráticos ou até mesmo com obras que passam longe da sala de aula. Se os índices de desigualdade de renda provocam dificuldades no acesso à escola, o acesso a esta não garante igualdade de oportunidades educacionais, pois ela própria é afetada por problemas de diferenciação de disponibilidade de recursos, o que ocasiona discrepâncias quanto à qualidade de material físico e de capacitação humana que ela pode oferecer.

Em suma, o mal uso dos recursos públicos, a inépcia, a refração dos controles democráticos e favorecimentos permitem caracterizar o panorama atual da educação no país. Por que então não mudar a receita? Bresser Pereira afirma que "...muitos são os privatizadores da coisa pública" e "....cabe aos economistas um papel estratégico neste processo, na medida em que sejam capazes de definir os critérios que permitam distinguir a despesa pública legítima da ilegítima" (Bresser Pereira, 1996, p.34).

Considerando a atual estrutura institucional e a política econômica vigente, o fato de melhorarmos as escolas não implicará na solução dos problemas das classes sociais, nem poderemos acreditar que a escola será igual para todos, pelo simples fato de que "todos" não moram no mesmo lugar, não têm acesso às mesmas coisas, não têm a mesma formação familiar etc.

Podemos supor que o problema da educação não é só um problema financeiro, mas também político. Como dizemos no jargão econômico, é um problema de má alocação de recursos e não 
de falta de recursos. Então, por que não se resolve o problema? Porque, pensando "politicamente", é mais vantajoso alimentar os alunos do que remunerar decentemente os professores, que se tornam profissionais despreparados, desmotivados ou, até mesmo, na pior das hipóteses, abandonam o magistério. Não existe lucro político em educar pessoas e sim em construir prédios. O homem público tende a pensar em fazer hoje o que pode transformar em votos no futuro, uma demonstração bem modesta de "rent-seeking".

O caminho pode, por exemplo, seguir as vias da descentralização, com a participação maior de instâncias que não pertençam ao aparato estatal. Descentralização não significa o desmanche do Estado, mas uma redistribuição mais racional de suas atividades, delimitando-se o público do estatal, procurando legitimar mecanismos de controle que levem, ao invés da intervenção, a uma maior equidade na sociedade. A noção de "público não estatal" tem que se basear na imagem de uma democracia onde os atores que a constituam sejam solidamente resgatados.

Alguns economistas acreditam que o que vai regular a educação é o mercado e que a privatização da mesma tende a uma maior eficiência, denotando um caráter "produtivista" ao conceito de educação, onde a rede escolar estaria sujeita às regras de mercado, deixando que a universalidade da educação resulte da preferência dos indivíduos, ao invés da coerção legal, amparada pela ampla oferta de vagas gratuitas no ensino público (entenda-se ensino público como o ensino oferecido, controlado e executado pelo setor público). Porém, esses estudiosos não propõem novas formas de políticas, que tornem a educação um mecanismo eficiente e não excludente, e que promovam a equidade social.

Por outro lado, os defensores do ensino para todos, de responsabilidade estatal, e não formador de insumos para o mercado, não entendam que a maioria da população que estuda, estuda para conseguir maiores chances na vida e não por mero prazer de estudar.

Embora a educação seja hoje um direito prio- ritário do cidadão, o Estado não tem apresentado condições de manter um aparato gigantesco para ofertar, com qualidade, um produto importante tanto para a economia como para a sociedade de qualquer país e que seja pela escassez de recursos como pela incompetência gerencial dos governos.

Ao mesmo tempo, promover as preferências individuais é um dos alicerces do modelo democrático e proporcionar mecanismos para que os indivíduos tenham condições de ascender a posições melhores é a base para a solidificação e democratização da sociedade civil, anseios que, com absoluta certeza, não são prioridades do setor privado.

Políticos e administradores buscam hoje fórmulas "mágicas", para resolver a crise do setor educativo, para formar força de trabalho qualificada para o sistema, como computadores para analfabetos, educação à distancia e campanhas para erradicar o analfabetismo, medidas que na verdade são usadas como paliativo para responder a algumas pressões sociais, porém tão longe da realidade do país que é impossível levá-las a sério. Ao mesmo tempo tornou-se senso comum que uma das causas do alto nível de desemprego é a falta de qualificação profissional, invertendo a relação causa-conseqüência: não é a política econômica que não gera emprego e sim a falta de mão-de-obra qualificada que impede o progresso do país. A grosso modo, entre um Estado que não define seu papel e um setor privado que cada vez mais solicita qualificações para postos de trabalhos que não necessitam dessa demanda, o culpado é o trabalhador que não acompanha as mudanças tecnológicas.

O Ministério da Educação e Cultura (MEC), que deveria influir nos destinos da educação, é um órgão subalterno a outros "considerados mais importantes”. Desta forma, a educação está vinculada aos interesses econômicos e políticos de cada governo, provocando uma descontinuidade de planejamento. Cabe ao MEC alocar recursos e divulgá-los, "escutar" o que cada região tem a dizer sobre suas necessidades pedagógicas e con- 
trolar, não o nível de ensino em si, mas o nível de aprendizado.

Acreditamos que a educação e, principalmente, o ensino fundamental devam ser reorientados para as necessidades populares, fornecendo condições para que as pessoas resgatem o seu papel de agentes transformadores da sociedade.

A reformulação do modelo de políticas educacionais poderia proporcionar mais eficiência dos usos dos recursos, diminuição da patronagem política, maior controle por parte da comunidade sobre os gastos nas escolas e, conseqüentemente, menores possibilidades de corrupção.

O grande desafio é a gestão dos recursos materiais e humanos para garantir a aprendizagem, na tentativa de fortalecer e valorizar a eqüi- dade escolar, o que inclui, além das vantagens mencionadas acima, fórmulas de combinar atuações e não a privatização pura e simples do sistema, mas sim, de articulação entre o setor público e privado, definindo graus de inserção, controle e regulamentação do governo nos serviços educacionais.

Longe da pretensão de tentar qualquer solução pedagógica, deve-se questionar se a causa da baixa qualidade do ensino não está na falta de recursos, mas sim em como são distribuídos, que as estratégias de descentralizar e dar maior autonomia aos estabelecimentos de ensino e a adoção de escolas públicas não estatais poderiam ser o início da reconstituição do espaço político da sociedade.

\section{REFERÊNCIAS BIBLIOGRÁFICAS}

ANDERSON C.A. Contexto social do planejamento educacional. Cadernos de Pesquisa. São Paulo: Fundação Carlos Chagas, 1973 .

ARROW, K. Social Choice and individual Values. Yale: Yale University Press, 1951

BECKER, Gary S. Investiments in human capital: a theorical analysis. Readings in the economic of education. UNESCO, Paris: 1968. BLAUG, Mark. Introdução à economia da educação. Porto Alegre: Globo, 1975.

BRESSER PEREIRA, L.C., MARAVALL, J.M. PRZERWORSKI, A, Economic Reforms in New Democracies, Cambridge: Cambridge University Press, 1993

CASTRO, Cláudio de Moura. Desenvolvimento econômico, educação e educabilidade. Rio de Janeiro: Tempo Brasileiro, 1972. Planejamento educacional e desenvolvimento. In Simpósio sobre Planejamento da Educação. São Paulo: SBPC, 1972.

Educação brasileira: consertos e remendos. Rio de Janeiro: Rocco, 1994.

CEPAL/UNESCO Educacion y conocimiento: Eje de la transforma-cion produtiva con eqüidade. Santiago, Chile: 1992.

CORAGGIO, J.L. Desenvolvimento humano e educação. São Paulo: Cortez, 1996.

DE TOMMASI, L, WARDE, M.J. \& HADDAD, S. (orgs.). O Banco Mundial e as políticas educacionais. São Paulo: Cortez, 1996.

DOCUMENTOS Oficiais sobre Planos de Governo, Ministério do Planejamento e Presidência da República. (de 1962 a 1994)

DOCUMENTOS Oficiais sobre Planos de Educação, Ministério da Educação e Cultura. (de 1962 a 1996).

FREIRE, Paulo. Educação e mudança. Rio de Janeiro: Paz e Terra, 1985.

FRIGOTTO, Gaudêncio. Educação e a crise do capitalismo real. São Paulo: Editora, 1995

FURTADO, Celso. Desenvolvimento e subdesenvolvimento, Rio de Janeiro: Fundo de Cultura, 1961.

- Brasil e a Construção Interrompida, São Paulo: Paz e Terra, 1992

GALBRAITH, J. K. O Novo estado industrial. São Paulo: Abril Cultural, 1982

GATTI, Bernadete A. Problemas da educação básica no Brasil: a exclusão das massas populacionais. OEA, Projeto Multinacional de Educação Básica, Washington, 1990

GINZBERG, Eli. Aptidões para o desenvolvimento. Diálogo, out/dez 1972.

HABERMAS, J Mudança Estrutural da Esfera Pública, Rio de Janeiro, Biblioteca Tempo Universitário, 1984

HAVEMAN, R.H. \& MARGOLIS, J. Un Análisis del gasto y las políticas gubernamentales. México: Fondo de Cultura Econômica, 1992.

KEYNES, J.M. A Teoria geral do emprego, do juro e da moeda. São Paulo: Atlas, 1988.

MARX, K. \& ENGELS, F. Textos sobre educação e ensino. São Paulo: Moraes, 1983.

OLSON, M. The Logic of Collective Action: Public Goods and the Theory of Groups, Harvard: Harvard Press, 1965.

PARNES, H.S. Relation of occupation to educational qualification. Economics of Education . Middlesex: England, Penquim Books, 1968.

PLANO de Desenvolvimento do Ensino Fundamental e de Valorização do Magistério. Ministério da Educação e Cultura. Brasília, 12/09/1995. 
PREBISH, Raul. Transformação e desenvolvimento: a grande tarefa da América Latina, Rio de Janeiro, FGV, 1993.

PRESIDENT's COMMISSION ON HIGHER EDUCATION. Education for free men. Higher education for american democracy, New York: Harper, 1947.

PRZEWORSKY, A Estado e Economia no Capitalismo, Rio de Janeiro: Relume-Dumará, 1995

RIBEIRO, Sérgio Costa. A Pedagogia da repetência. Estudos Avançados, vol. 12, maio/agosto, 1990.

SALM, Cláudio. As relações entre capitalismo e educação: prolegômenos. Estudos Econômicos, São Paulo, v.22, IPE-USP, p.49 a p.62, 1992.

SAVIANI, Demerval. Neo-Liberalismo ou pós-liberalismo? educação pública, crise do estado e democracia na América Latina. Estado e Educação. Campinas: Papirus, 1992.

SCHULTZ, Theodore W. O Capital humano: investimentos em educação e pesquisa. Rio de Janeiro: Zahar, 1973.

SEN, A K. Internal Consistency of Choice, Econometrica, vol.61, nr 03, May, 1993

TOURAINE, Alain. Educação permanente e sociedade industrial. Revista Brasileira de Estudos Pedagógicos. Jan/mar, 1969

VAIZEY, John. Economia da educação. São Paulo: IBRASA. 1968. 